\title{
BELT \\ Brazilian English Language Teaching Journal
}

\section{Modelo didático do gênero artigo científico: um contributo para o ensino do Português como Língua Adicional}

\author{
Rute Alves Rosa (1) \\ Universidade NOVA de Lisboa, Liasboa, Portugal.
}

\section{RESUMO}

Neste artigo, apresentamos um modelo didático do gênero artigo científico, destinado a orientar a intervenção dos professores no ensino do Português como Língua Adicional no contexto acadêmico português. Para tal, tendo como base o quadro teórico do Interacionismo Sociodiscursivo (Bronckart, [1997]1999) e os princípios da Didática dos Gêneros (Dolz \& Schneuwly, 2004), fazemos uma análise textual descritiva de dez exemplares que se inscrevem no gênero, seguindo-se o modelo didático, no qual sistematizamos as características sociais, contextuais e composicionais do artigo científico. Com esta proposta, sublinhamos a importância do desenvolvimento de dispositivos de didatização que facultem a apropriação de gêneros acadêmicos, como é o caso do artigo científico, e demonstra-se que o uso dos gêneros no ensino do Português como Língua Adicional possibilita a aprendizagem da língua nas suas diferentes esferas de utilização.

Palavras-chave: Interacionismo Sociodiscursivo; Português como Língua Adicional; Modelo didático; Artigo científico.

\section{A didactic model for the genre 'scientific article': contributions to the teaching of Portuguese as an Additional Language}

\section{ABSTRACT}

In this paper, we present a didactic model of the genre 'scientific article', which intends to guide the work of teachers of Portuguese as an Additional Language in the Portuguese academic context. To this end, we perform a descriptive analysis of ten texts that fall into the genre in question, followed by the didactic model, in which we systematize the social, contextual and compositional characteristics of the scientific article. Our approach is based on the theoretical framework of Sociodiscursive Interactionism (Bronckart, [1997]1999) and on the principles of Didactics of Genres (Dolz \& Schneuwly, 2004). This work aims to highlight the importance of developing didatization devices that allow the appropriation of academic genres, such as the scientific article, and it also demonstrates that the use of genres in the teaching of Portuguese as Additional Language promotes the learning of this language as far as its different spheres of use are concerned.

Keywords: Sociodiscursive Interactionism; Portuguese as an Additional Language; Didactic model; Scientific article. 


\section{INTRODUÇÃO}

Este trabalho ${ }^{1}$ enquadra-se no projeto de investigação em curso, desenvolvido no âmbito do Doutoramento em Linguística do Texto e do Discurso, no qual, privilegiando o quadro teórico do Interacionismo Sociodiscursivo (ISD), se desenvolve a noção de padrão discursivo, um dispositivo de caracterização diferencial dos gêneros, a partir da articulação das noções de plano de texto e tipos discursivos.

O artigo científico, um dos gêneros contemplados no projeto de investigação, é um gênero acadêmico essencial para a difusão de conhecimentos e partilha de investigações em diferentes áreas científicas. Porém, no contexto português, a maioria dos alunos só entra em contato com exemplares do gênero quando ingressa no ensino superior, revelando várias dificuldades, nomeadamente na interpretação e produção textuais.

Quanto ao ensino do Português como Língua Adicional, embora grande parte das instituições do ensino superior em Portugal disponha de cursos de português para estrangeiros orientados pelas abordagens metodológicas do QECR ${ }^{2}$, no qual se valoriza a utilização de estratégias que propiciem a utilização da língua em contexto, os gêneros e as necessidades comunicativas mais específicas dos aprendentes, como, por exemplo, a aprendizagem do uso da língua na esfera acadêmica, fundamental para os alunos estrangeiros que frequentam o ensino superior em Portugal, ainda são um pouco secundarizadas em contexto formal de ensino.

Além disso, verifica-se que os dispositivos de didatização dos gêneros (modelos didáticos e sequências didáticas) são, na sua maioria, destinados à formação de professores de Português Língua Materna, nos ensinos básico e secundário, não sendo considerado o ensino superior, nem a sua aplicabilidade no ensino do Português como Língua Adicional, conforme se observa nos documentos Programa e Metas Curriculares do Português e Aprendizagens Essenciais ${ }^{3}$. Deste ponto de vista, por um lado, é necessário desenvolver dispositivos de didatização dos gêneros que facultem a apropriação de gêneros acadêmicos, como é o caso do artigo científico e, por outro, considerar que o uso dos gêneros no ensino do Português como Língua Adicional possibilita a aprendizagem da língua nas suas diferentes esferas de utilização, contribuindo, assim, para a apropriação das práticas comunicativas em uso e, consequentemente, para a integração social dos aprendentes.

\footnotetext{
$\overline{1} \mathrm{O}$ presente trabalho é financiado por fundos nacionais portugueses, através da FCT - Fundação para a Ciência e Tecnologia, como parte do projeto do Centro de Linguística da Universidade NOVA de Lisboa - UID/LIN/03213/2013 e da bolsa de investigação PD/BD/113974/2015, ao abrigo do Programa de Doutoramento FCT “KRUse - Knowledge, Representation \& Use".

2 A sigla QECR corresponde ao Quadro Europeu Comum de Referência para as Línguas: Aprendizagem, ensino, avaliação (QECR), documento do Conselho da Europa, elaborado no âmbito do Projeto Políticas Linguísticas para uma Europa Plurilingue e Multicultural. Disponível em: http://www.dge.mec.pt/sites/ default/files/Basico/Documentos/quadro_europeu_comum_referencia.pdf

${ }^{3}$ O Programa e Metas Curriculares dō Portuguêês do Ēnsino Básico foca, sobretudo, as distinções gêneros escolares/gêneros literários, bem como as características narrativas e expositivas dos textos. Já o Programa e Metas Curriculares de Português do Ensino Secundário, embora este valorize o ensino do texto literário, os conteúdos programáticos já contemplam a leitura de textos de divulgação científica cf. Buescu et al., 2014; 2015). Relativamente às Aprendizagens Essenciais para o $1^{\circ}, 2^{\circ}$ e $3^{\circ}$ ciclos do Ensino Básico, homologadas a 19 de julho de 2018, destaca-se a importância dada à pluralidade dos gêneros textuais. Disponível em: http://www.dge.mec.pt/aprendizagens-essenciais-ensino-basico
} 
Neste sentido, assumindo-se a perspectiva de que a apropriação dos gêneros é um "mecanismo fundamental de socialização, de inserção prática nas atividades comunicativas humanas" (Bronckart ([1997]1999, p. 103), entendemos que os gêneros, como mediadores no processo de ensino, constituem instrumentos facilitadores da aprendizagem da língua. Deste ponto de vista, o objetivo desta proposta é apresentar um modelo didático do gênero artigo científico, destinado a orientar a intervenção dos professores de Português como Língua Adicional no contexto acadêmico português ${ }^{4}$.

Para tal, num primeiro momento, abordamos os pressupostos que fundamentam esta proposta, nomeadamente os princípios teóricos e metodológicos do quadro do Interacionismo Sociodiscursivo (Bronckart, [1997]1999), no qual destacamos as noções de plano de texto e de tipos discursivos. Numa segunda etapa, depois de uma breve contextualização dos princípios da Didática dos Gêneros (Dolz \& Schneuwly, 2004), procedemos a uma análise textual descritiva de um corpus constituído por dez exemplares, seguindo-se o modelo didático, no qual procuramos sistematizar as características sociais, contextuais e composicionais do gênero artigo científico.

\section{A PERSPECTIVA DO ISD}

Para o ISD, a linguagem corresponde a uma forma de atividade nas diferentes esferas da interação humana e os textos são, deste modo, produtos da atividade humana e das suas necessidades, sendo, por isso, os correspondentes empíricos e linguísticos das atividades de linguagem. De acordo com esta perspectiva, o texto singular é, assim, resultado de uma "ação de linguagem situada", correspondendo a uma realização concreta do sistema linguístico numa determinada situação comunicativa (Bronckart, [1997]1999, p. 75). Porém, como sublinha Bronckart (2010, p. 28), apesar de todo o texto mobilizar unidades linguísticas de uma língua natural, este não é em si mesmo uma unidade linguística, mas uma unidade comunicativa, dado que as suas condições de abertura e fechamento não derivam do linguístico, sendo determinadas pela ação que o gerou.

Deste ponto de vista, a organização e funcionamento dos textos dependem, para além dos recursos e das regras de uma língua natural, das propriedades das atividades com que se articulam e das condições contextuais da situação produção e das escolhas individuais de cada produtor. Considerando estas relações de dependência, o ISD privilegia uma abordagem descendente (Voloshinov, [1929]1977), isto é, as produções de linguagem devem ser relacionadas, primeiramente, com a atividade humana em geral, depois das atividades de linguagem para os textos e, por último, dos textos para as unidades linguísticas (Bronckart, [1997]1999, p. 107).

Por outro lado, um dos pressupostos centrais do quadro teórico do ISD, e aquele que assumimos, é o de que qualquer texto é produto da interação entre uma ação de linguagem e um dos modelos de gêneros sincro-

${ }^{4}$ Em trabalhos futuros, pretendemos considerar as práticas de Ensino de Português como Língua Adicional no contexto acadêmico brasileiro (Corno, 2001; Schoffen, 2009). 
nicamente disponíveis (Bronckart, 1996, p.10). Tal como define Coutinho (2006, p. 4):

os gêneros são entendidos como 'formas comunicativas' elaboradas pela atividade de gerações precedentes e sincronicamente disponíveis, em termos de arquitexto, como instrumentos ou modelos que, no dizer de Bronckart, se apresentam aos utentes da língua sob a forma de nebulosa (onde coexistem gêneros estabilizados e conjuntos de textos sem fronteiras fixas ou nítidas).

Assim, o emissor que se encontra numa situação de ação de linguagem específica, a partir do conhecimento que tem do conjunto de gêneros (arquitextualmente disponíveis) e da forma como avalia e perspectiva a situação da ação (mediante as representações do contexto ${ }^{5}$ ), seleciona o modelo de gênero que considera mais adequado e adapta-o à situação comunicativa (Bronckart, 1996, p. 12).

Por outro lado, este processo de seleção e adaptação envolve o conhecimento dos contextos de uso dos gêneros, assim como das suas características linguísticas e estruturais. Deste ponto de vista, como sublinha Coutinho (s/d):

a maior ou menor familiaridade com um determinado gênero - isto é, com as regularidades situacionais, funcionais e organizacionais que the estão associadas - funcionará como fator facilitador, tanto na perspectiva da produção como na da interpretação.

\subsection{Tipos discursivos e plano de texto}

Embora os gêneros sejam potencialmente heterogêneos e maleáveis, uma das suas características é a ocorrência de diferentes segmentos que identificamos através da regularidade de unidades linguísticas que se articulam na sua constituição. A este tipo de diferentes segmentos constituídos por formas linguísticas específicas, Bronckart designa de discurso, que consoante as regularidades linguísticas, pode ser classificado em tipos discursivos (Bronckart, [1997]1999, p. 138). Considerados em função das suas condições de produção, os tipos discursivos correspondem a diferentes planos da enunciação e semiotizam quatro mundos discursivos: interativo, teórico, relato interativo e narração. Conforme se apresenta no quadro abaixo, estes mundos discursivos surgem da relação estabelecida, por um lado, entre as coordenadas temporais que organizam textualmente os conteúdos temáticos e as coordenadas temporais da situação de enunciação e, por outro, entre as instâncias de agentividade mobilizadas no texto e as instâncias de agentividade associadas à situação de produção (Miranda, 2008, p. 85).

\footnotetext{
${ }^{5}$ No quadro do ISD, o contexto é entendido como o conjunto de parâmetros físicos (emissor, receptor, momento e lugar) e sociosubjetivos (quadro social da ação, papéis sociais do enunciador e destinatário, finalidade) que influenciam a construção textual (Bronckart [1997]1999, p. 93).
} 
Quadro 1. Tipos discursivos.

\begin{tabular}{|c|c|c|c|}
\hline & & \multicolumn{2}{|c|}{ Organização temporal } \\
\hline & & $\begin{array}{c}\text { Conjunção } \\
\text { EXPOR }\end{array}$ & $\begin{array}{l}\text { Disjunção } \\
\text { NARRAR }\end{array}$ \\
\hline \multirow{2}{*}{ Organização agentiva } & Implicação & Interativo & Relato interativo \\
\hline & Autonomia & Teórico & Narração \\
\hline
\end{tabular}

Fonte: Extraído e adaptado de Bronckart ([1997]1999, p. 157).

Como ilustra o Quadro 1, a construção dos quatro mundos discursivos baseia-se em dois tipos de operações: organização temporal e organização agentiva.

A organização temporal diz respeito à localização temporal dos acontecimentos representados em relação à situação de produção. A construção das coordenadas temporais que organizam o conteúdo temático pode concretizar-se de duas formas: se as coordenadas temporais que organizam os conteúdos temáticos expressarem acontecimentos simultâneos à situação de enunciação, há um valor de conjunção temporal. Neste caso, temos a construção de mundos discursivos na ordem do expor: teórico e interativo. Por outro lado, se as coordenadas temporais verbalizadas expressarem acontecimentos que não são simultâneos à situação de enunciação, há um valor de disjunção temporal e, neste caso, temos a construção de mundos discursivos na ordem do narrar: discurso narração e relato interativo. Deste ponto de vista, aquilo que distingue a ordem do narrar da ordem do expor é a relação que é estabelecida entre a organização temporal dos conteúdos tematizados e as coordenadas do mundo ordinário. Estas operações de construção da organização temporal cruzam-se com duas possibilidades de organização agentiva: implicação e autonomia. As instâncias de agentividade verbalizadas no texto podem ter um valor de implicação, quando se verifica que há inscrição dos parâmetros da situação da ação de linguagem no texto, nomeadamente do emissor, do receptor, ou referências à sua localização no tempo e espaço da ação. Neste caso, são construídos mundos discursivos implicados no mundo ordinário: discurso interativo e relato interativo. Por outro lado, há um valor de autonomia, quando os parâmetros da situação da ação não se manifestam textualmente, sendo, assim, construídos mundos discursivos autônomos do mundo ordinário: discurso teórico e narração.

Os mundos discursivos constituem, desta forma, mundos virtuais textualmente construídos e evidenciados pelo tipo de relação que mantêm com o mundo ordinário/real, isto é, com o mundo dos agentes de produção. Deste ponto de vista, os tipos discursivos estão necessariamente associados a operações do pensamento humano, pois correspondem à verbalização de diferentes operações psicológicas e modos de raciocínio específicos. Segundo Bronckart (2004, p. 107), o discurso interativo está associado a raciocínios práticos, o discurso teórico corresponde à verbalização de raciocínios lógicos (ou quase lógicos) e o relato interativo e a narração constituem a expressão de raciocínios causais-cronológicos. Neste sentido, os tipos discursivos são, simultaneamente, operações psicológicas e operações discursivas, correspondendo, por um lado, no plano abstrato, a arquétipos psicológicos e, por outro, no nível concreto, a tipos linguísticos que dizem respeito à 
concretização/verbalização dessas operações do pensamento humano. Por este motivo, tal como sublinha Bronckart (2004, p. 107), "os tipos de discurso constituem condição de exercício (e de aprendizagem) dos diferentes modos de raciocínio".

Uma outra propriedade dos textos e dos gêneros que contribui para a sua caracterização é o plano de texto que, tal como os tipos discursivos, integra a infraestrutura geral - a camada mais profunda de um dos instrumentos de análise do ISD, o modelo da arquitetura interna dos textos. O plano de texto corresponde à "organização de conjunto do conteúdo temático", sendo responsável pela organização global do texto e sendo, por isso, bastante importante na organização dos tipos discursivos (Bronckart, [1997] 1999, p. 120).

No âmbito da Linguística Textual, Jean-Michel Adam, o autor que mais tem desenvolvido esta noção, sublinha o papel do plano de texto como principal fator unificador da estrutura composicional (Adam, 2008). Segundo Adam, o plano de texto diz respeito à dispositio da Retórica Clássica. Contudo, observando que o modelo da Retórica não permite dar conta de todas as possibilidades de planos de texto, o autor opta por distinguir os planos convencionais dos planos ocasionais, em função da maior ou menor fixação dos gêneros (Adam, 2008, p. 256).

O plano de texto é visível no processo de leitura e reconstruído na escrita (ou na oralidade), assumindo, por isso, um papel fundamental na leitura, interpretação e produção textuais (Bronckart, [1997]1999, p. 120). Segundo Silva (2016, p. 193), o plano de texto "consiste na distribuição dos conteúdos manifestados e, em suporte escrito, na segmentação formal atestada num texto".

Deste ponto de vista, tal como sublinham Silva (2016, p. 193) e Gonçalves (2011, p. 9), para analisar o plano de texto, é necessário considerar a distribuição dos conteúdos e a segmentação formal, isto é, identificar as diversas seções que constituem o texto e a forma como estas se distribuem no espaço textual. Porém, importa sublinhar também que, na maioria dos gêneros, os mecanismos de segmentação dependem dos conteúdos tematizados e a distribuição dos conteúdos depende da sua seleção prévia (Silva, 2016, p. 194). Na nossa perspectiva, o plano de texto corresponde, assim, ao modo particular como a forma evidenciada pela segmentação organiza os conteúdos na superfície textual. Isto significa, por um lado, que a mesma forma pode organizar diferentes conteúdos e, por outro, que os mesmos conteúdos podem ser organizados por diferentes formas. Para apreender o plano de texto, é, então, necessário considerar os organizadores textuais (gráficos, linguísticos e pontuação) que segmentam, delimitam e agrupam as unidades no espaço textual (Coutinho, 2004). Em suma, o plano de texto e os tipos discursivos são, assim, duas propriedades relevantes dos gêneros a considerar nos instrumentos de transposição didática.

\section{MODELO DIDÁTICO DO GÊNERO ARTIGO CIENTÍFICO}

Para Dolz e Schneuwly (1999), o uso dos gêneros como recursos didáticos tem dois objetivos específicos: 
aprender a dominar o gênero, primeiramente, para melhor conhecê-lo ou apreciá-lo, para melhor saber compreendê-lo, para melhor produzi-lo na escola ou fora dela e, em segundo lugar, para desenvolver capacidades que ultrapassam o gênero e que são transferíveis para outros gêneros próximos ou distantes (Dolz \& Schneuwly, 1999, p. 10).

A didatização dos gêneros textuais tem vindo a ser concretizada através de dois tipos de dispositivos: a sequência didática e o modelo didático. $\mathrm{O}$ primeiro, a sequência didática, é um dispositivo prático constituído por módulos de ensino que integram um conjunto de atividades escolares organizadas sistematicamente em torno das diferentes dimensões de um gênero textual. Isto significa que o objetivo de uma sequência didática é ajudar o aluno a apropriar-se de um determinado gênero (contextos de uso e caraterísticas estruturais), "permitindo-lhe, assim, escrever ou falar de uma maneira mais adequada numa dada situação de comunicação" (Schneuwly \& Dolz, 2004, p. 97). Quanto ao modelo didático, este é um dispositivo teórico que procura evidenciar as dimensões ensináveis (ou algumas delas) de um determinado gênero, sendo, assim, destinado a orientar as intervenções dos professores (Schneuwly \& Dolz, 1999, p. 12). Dado que a elaboração de uma sequência didática requer o acesso a textos produzidos em contexto de ensino, a nossa proposta circunscreve-se à elaboração de um modelo didático, ou seja, a um dispositivo teórico que descreve as principais características do gênero, evidenciando algumas das suas dimensões ensináveis.

\subsection{Metodologia e corpus}

Tendo em conta que a elaboração de um modelo didático implica a análise de textos que se inscrevam no gênero (De Pietro, Erard \& Kanemam-Pougatch, 1996), constituímos um corpus que integra dez exemplares do gênero artigo científico inscritos em duas áreas científicas - Direito e Ciências Farmacêuticas - por serem relativamente contrastivas. Conforme apresentamos no quadro abaixo, para a identificação dos textos, utilizamos uma sigla com as iniciais do gênero e das duas áreas científicas consideradas.

Quadro 2. Corpus.

\begin{tabular}{|c|c|c|}
\hline Áreas & Siglas & Links de acesso aos textos \\
\hline \multirow{5}{*}{ 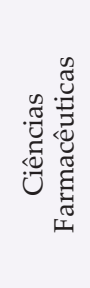 } & ACF1 & http://www.actafarmaceuticaportuguesa.com/index.php/afp/article/view/60 \\
\hline & ACF2 & http://www.actafarmaceuticaportuguesa.com/index.php/afp/article/view/138 \\
\hline & ACF3 & http://www.actafarmaceuticaportuguesa.com/index.php/afp/article/view/8 \\
\hline & ACf4 & http://www.actafarmaceuticaportuguesa.com/index.php/afp/article/download/138/167 \\
\hline & ACf5 & http://www.actafarmaceuticaportuguesa.com/index.php/afp/article/view/8/108 \\
\hline \multirow{5}{*}{$\begin{array}{l}\text { 옴 } \\
\text { : }\end{array}$} & ACD1 & http://repositorio.ulusiada.pt/bitstream/11067/1189/1/LD_n4-5_3 \\
\hline & ACD2 & https://repositorio-aberto.up.pt/bitstream/10216/82568/2/102001.pdf \\
\hline & ACD3 & https://sigarra.up.pt/fdup/en/pub_geral.pub_view?pi_pub_base_id=101939 \\
\hline & ACD4 & http://hdl.handle.net/11328/702 \\
\hline & ACD5 & http://hdl.handle.net/1822/21650 \\
\hline
\end{tabular}


Em termos metodológicos, privilegiando uma abordagem descendente (Voloshinov, [1929]1977), das atividades sociais às propriedades dos textos, efetuamos uma análise textual qualitativa de cunho descritivo/comparativo, contemplando, em primeiro lugar, o funcionamento social do gênero, tendo em conta as atividades a que está associado, os parâmetros contextuais de ordem social e subjetiva, seguindo-se a dimensão composicional, considerando a configuração do plano de texto e os tipos discursivos mobilizados.

\subsection{Análise}

Quanto ao funcionamento social do gêneros, antes de mais, importa sublinhar que nem sempre existe uma relação clara e biunívoca entre os gêneros e atividades sociais, ou seja, num dado gênero podem interagir diferentes atividades e estas não estão ao mesmo nível. No caso do artigo científico, o gênero está associado à esfera de investigação no âmbito da atividade acadêmica que, por sua vez, depende da atividade científica de diferentes áreas. Embora tenhamos considerado artigos de duas áreas científicas, o artigo científico é um gênero que pode estar associado e ser mobilizado em muitos outros domínios científicos, como, por exemplo, História, Psicologia, etc. Por outro lado, a produção e a circulação dos textos também dependem das normas e diretrizes da atividade editorial que, por sua vez, também é regulada, numa relação de condicionamento mútuo, pela atividade de investigação e, mais especificamente, pela área científica com que se articula. Compreende-se, assim, que textos de diferentes áreas científicas, como é o caso dos exemplares considerados, sejam publicados de acordo com diferentes normas e que, também por isso, apresentem características distintas e singulares.

No que diz respeito ao contexto de produção dos textos, verifica-se que o artigo científico é um gênero associado a parâmetros contextuais de ordem social e subjetiva relativamente estáveis, como se apresenta no quadro abaixo.

Quadro 3. Dimensão contextual do gênero artigo científico.

\begin{tabular}{|c|c|c|}
\hline \multirow{4}{*}{ 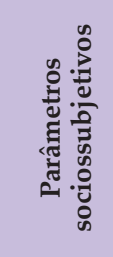 } & Papel social do enunciador(es) & Investigadores/docentes \\
\hline & Papel social do destinatário(s) & Investigadores/comunidade científica \\
\hline & Lugar Social & Instituição acadêmico-científica \\
\hline & Objetivo(s) da interação & $\begin{array}{l}\text { Apresentar um processo de investigação e/ou resultados } \\
\text { de uma pesquisa ou reflexão sobre um tema relevante } \\
\text { para a área científica }\end{array}$ \\
\hline \multicolumn{2}{|c|}{ Quadro social de circulação } & Revistas científicas nacionais \\
\hline
\end{tabular}

Como se sistematiza no quadro 3, o artigo científico é produzido no âmbito de uma instituição acadêmica, na qual o enunciador assume o papel social de investigador que produz um texto destinado à comunidade científica, tendo como finalidade apresentar um processo de investigação, resultados de uma pesquisa e/ou uma reflexão sobre um tema relevante para a respetiva área científica.

Do ponto de vista didático, a dimensão contextual é essencial, pois são os fatores que a integram que mais influenciam a produção dos textos inscritos 
no gênero, sendo, por isso, fundamental, em contexto formal de ensino, a reflexão sobre os papéis sociais do enunciador e do destinatário, ou seja, o aluno deverá considerar o papel social assumido por quem escreve e para quem se escreve, bem como o objetivo da escrita de um artigo científico. Além disso, é ainda de sublinhar o papel do contexto de circulação, dado que as revistas responsáveis pela publicação dos textos fornecem instruções específicas, não apenas relativas a questões formais, como, por exemplo, o tipo e tamanho de letra, mas também aspetos relacionados com a organização dos conteúdos no espaço textual, ou seja, relativos à planificação textual.

Quanto ao plano de texto, começando pelo peritexto dos exemplares de Ciências Farmacêuticas, verifica-se que o conteúdo temático aparece distribuído por várias seções maioritariamente convencionais, nomeadamente o título, nome dos autores, filiação institucional, etc. Estas unidades textuais são evidenciadas por diferentes mecanismos de organização textual gráficos (negrito, tipo/tamanho de letra, espaçamento e parágrafos).

Já no corpo de texto dos artigos Ciências Farmacêuticas, o conteúdo temático é distribuído por várias seções convencionais e ocasionais delimitadas através de mecanismos de organização textual gráficos (intertítulos destacados em negrito) e segmentadas através de parágrafos. Identificamos um nível hierárquico de seções verbais ou mistas, ou seja, temos imagens, gráficos, entre outros elementos, a ilustrar e/ou complementar aquilo que é expresso linguisticamente.

Nos artigos científicos de Direito, no peritexto, ocorrem também várias seções convencionais, como, por exemplo, título, autores, filiação acadêmica e referências, porém, nestes exemplares, ocorre a seção sumário, em vez do habitual resumo. Esta seção, que corresponde a um índice do artigo, anuncia a configuração do plano de texto, fornecendo ao leitor uma orientação prévia, no que se refere aos conteúdos tematizados no corpo do texto e à sua disposição no espaço textual (cf. Imagem 1).

Imagem 1. Índice (ACD2)

SUMÁRIO*:
1. Introdução
2. A recepção da pobreza na ordem jurídica
3. O conceito jurídico de pobreza e distinção de figuras afins:
3.1. Pobreza e mendicidade;
3.2. Pobreza e exclusão social;
3.3. Pobreza e desemprego;
3.4. Pobreza e trabalho (in-work poverty)
4. Os direitos dos pobres a nível do direito internacional:
4.1. Direito internacional comum;
4.2. Direito europeu não comunitário
4.3. Direito europeu comunitário
5. Direito interno
6. Pobreza e preconceitos jurídicos
7. Epílogo
Bibliografia


No corpo do texto dos artigos de Direito, o conteúdo temático aparece distribuído por seções ocasionais, exclusivamente verbais, delimitadas através de mecanismos de organização textual gráficos (intertítulos a negrito) e segmentadas, tal como nos artigos de Ciências Farmacêuticas, através de parágrafos. Diferentemente dos artigos de Ciênciais Farmacêuticas, nos exemplares de Direito, os conteúdos tematizados são organizados em dois ou mais níveis hierárquicos de seções.

Uma diferença importante entre os textos selecionados é que nos exemplares da área de Ciências Farmacêuticas predomina a descrição de processos experimentais, como é explicitado pelos intertítulos que marcam a abertura e fechamento das seções, delimitando-as no espaço textual (Métodos; resultados e discussão, ACF1; Materiais e métodos; resultados e discussão, ACF2). Isto significa que, nesta área, os conteúdos tematizados são ordenados/distribuídos de acordo com as diversas etapas de um processo de investigação. Já nos artigos de Direito, os conteúdos aparecem distribuídos de acordo com os temas selecionados, não tendo, por isso, a previsibilidade dos textos de Ciências Farmacêuticas, no que respeita à organização e distribuição dos conteúdos (3. Dificuldade (e necessidade) de harmonização dos vários regulamentos comunitários no âmbito do Direito Internacional Privado da família e das sucessões. Alguns exemplos, ACD3). Observa-se, assim, que as duas formas de fazer e divulgar ciência em uso nas duas áreas científicas se refletem na configuração do plano de texto, sendo mais previsível, quando se expõe um processo experimental (ACF) e menos, quando é tematizado um tema objeto de reflexão (ACD). Nesta perspectiva, o modo como os conteúdos tematizados aparecem distribuídos depende, em grande medida, das especificidades das áreas científicas, nomeadamente no que diz respeito à natureza dos processos de investigação privilegiados e aos temas contemplados/admitidos.

Neste sentido, por um lado, verifica-se que os exemplares analisados apresentam características transversais, nomeadamente a presença de seções peritextuais que explicitam a autoria dos textos e que indiciam os conteúdos dos mesmos (resumo, abstract, sumário, palavras-chave, keywords), assim como a organização sequencial e/ou hierárquica dos conteúdos em seções graficamente delimitadas e, por outro, observam-se divergências entre os exemplares decorrentes das especificidades das duas áreas científicas.

No que diz respeito à ocorrência dos tipos discursivos, embora predomine o discurso teórico, este articula-se, pontualmente, com os discursos narração e interativo, em encaixe, ocorrendo também variantes dos tipos discursivos, nos segmentos em que se articulam em fusão ${ }^{6}$. Por outro lado, apesar de nenhum tipo discursivo ser específico do gênero, verifica-se que estes ocorrem associados a conteúdos específicos. O discurso teórico, nos exemplares de Direito, ocorre nos momentos em que são tematizados aspetos gerais associados ao tema central do artigo, ou seja, quando o produtor expõe verdades autônomas, independentes da situação de

\footnotetext{
${ }^{6}$ Em encaixe, os tipos de discursivos emergem delimitados e ordenados, ou seja, é explícita a relação de dependência e subordinação entre os segmentos. Em fusão, os diferentes tipos de discursivos integram-se num mesmo segmento, não sendo, por isso, claras as suas fronteiras (Bronckart [1997] 1999, pp. 120-121).
} 
produção. Nos exemplares de Ciências Farmacêuticas, o discurso teórico predomina nos momentos de descrição do processo de investigação. A conjunção temporal e a autonomia das instâncias de agentividade são marcadas através da exploração de tempos verbais do plano do discurso ${ }^{7}$, nomeadamente formas no presente do indicativo sem valor dêitico, bem como através da ausência de frases não declarativas e de formas linguísticas que remetam para a pessoa, espaço, tempo da enunciação, como ilustram os excertos que se seguem.

Quadro 4. Discurso teórico (ACD2/ACF1).

Falar da pobreza (e dos pobres) e do seu enquadramento na ordem jurídica constitui um aspecto parcelar de um complexo e multidisciplinar problema, relativamente ao qual, importa reconhecer apesar da crescente relatividade dogmática co que as questões do social vêm sendo tratadas, o direito pode (e deve) desempenhar um papel relevante na sua redução ou eliminação, não obstante os principais meios para tal se situarem em campos que lhe são tecnicamente estranhos. (ACD2)

Os medicamentos não sujeitos a receita médica (MNSRM) apresentam vantagens e desvantagens. Do lado das vantagens destacam-se a maior acessibilidade a cuidados e a redução dos custos de tempo e monetários. (ACF1)

Quanto à ocorrência pontual do discurso interativo, enquanto nos artigos de Direito, este surge nos momentos de tomada de posição e na problematização (ACD1-ACD5), nos artigos de Ciências Farmacêuticas, é privilegiado nos momentos em que o autor (ou autores) se implica no processo de investigação.

Em todos os exemplares, o discurso interativo é marcado pela presença de formas linguísticas que expressam um valor de implicação do emissor, nomeadamente formas verbais na primeira pessoa e dêiticos temporais e espaciais, como nos excertos a seguir apresentados.

Quadro 5. Discurso interativo (ACD1/ACF5).

Quando aqui falo de direito penal, emprego a palavra em sentido lato, que inclui o processo penal, salvo se o contrário resultar do contexto. (ACD1)

Em jeito de conclusão final, e ainda que apenas a título de autores, parece-nos que no ano de 2013 (...). (ACF5)

7 Referimo-nos a um dos planos da enunciação que Bronckart ([1997]1999, pp. 168-175) retoma da distinção plano da história e plano do discurso de Benveniste. 
O discurso narração, nos artigos de Direito, é privilegiado quando são tematizados factos teóricos/históricos relevantes para o tema objeto de reflexão. Nos artigos de Ciências Farmacêuticas, aparece associado ao enquadramento teórico do processo de investigação, sendo tematizadas investigações anteriores. Este tipo discursivo de caráter autônomo e disjunto é marcado pela presença de organizadores temporais e tempos verbais do plano da história (pretérito perfeito e imperfeito), bem como pela ausência de unidades que remetam para o produtor e destinatários do texto

Quadro 6. Discurso narração (ACF1/ACD2).

Os dados foram recolhidos a partir de uma amostra de 1.206 adultos. Os resultados deste inquérito mostraram que $42 \%$ (...) (ACF1)

$\mathrm{Na}$ Idade Média, a luta contra a pobreza foi encarada como um problema de solidariedade, de proximidade e um dever de caridade cristã; o sistema de interdependência social em que assentava o regime feudal fazia com que a inserção dos pobres numa determinada comunidade constituísse uma garantia de protecção (...) (ACD2)

Nesta perspectiva, a emergência dos tipos discursivos no gênero não é totalmente aleatória. Os tipos discursivos mobilizados parecem depender, em parte, dos conteúdos tematizados e da sua organização, que, por sua vez, são regulados pelos diferentes domínios científicos, nomeadamente pelas práticas científicas em uso no contexto acadêmico português. Deste ponto de vista, estas características do gênero constituem alguns dos usos da língua portuguesa na esfera acadêmica, sendo, por isso, fundamental que estas sejam contempladas nos instrumentos didáticos destinados ao ensino do Português como Língua Adicional. Neste sentido, o ensino da língua através do ensino das características sociais, contextuais e composicionais observadas permitirá, por um lado, ensinar as especificidades dos usos língua portuguesa no âmbito acadêmico e, por outro, adaptar às necessidades comunicativas dos aprendentes.

Em seguida, apresentamos o modelo didático do artigo científico, no qual sistematizamos as principais características do gênero observadas. Neste dispositivo teórico, distinguimos duas dimensões que se cruzam, tendo em conta que são os fatores sociais e contextuais que influenciam as características composicionais dos textos. Na dimensão composicional, integramos o plano de texto e os tipos discursivos privilegiados. 
Quadro 7. Modelo didático do gênero artigo científico.

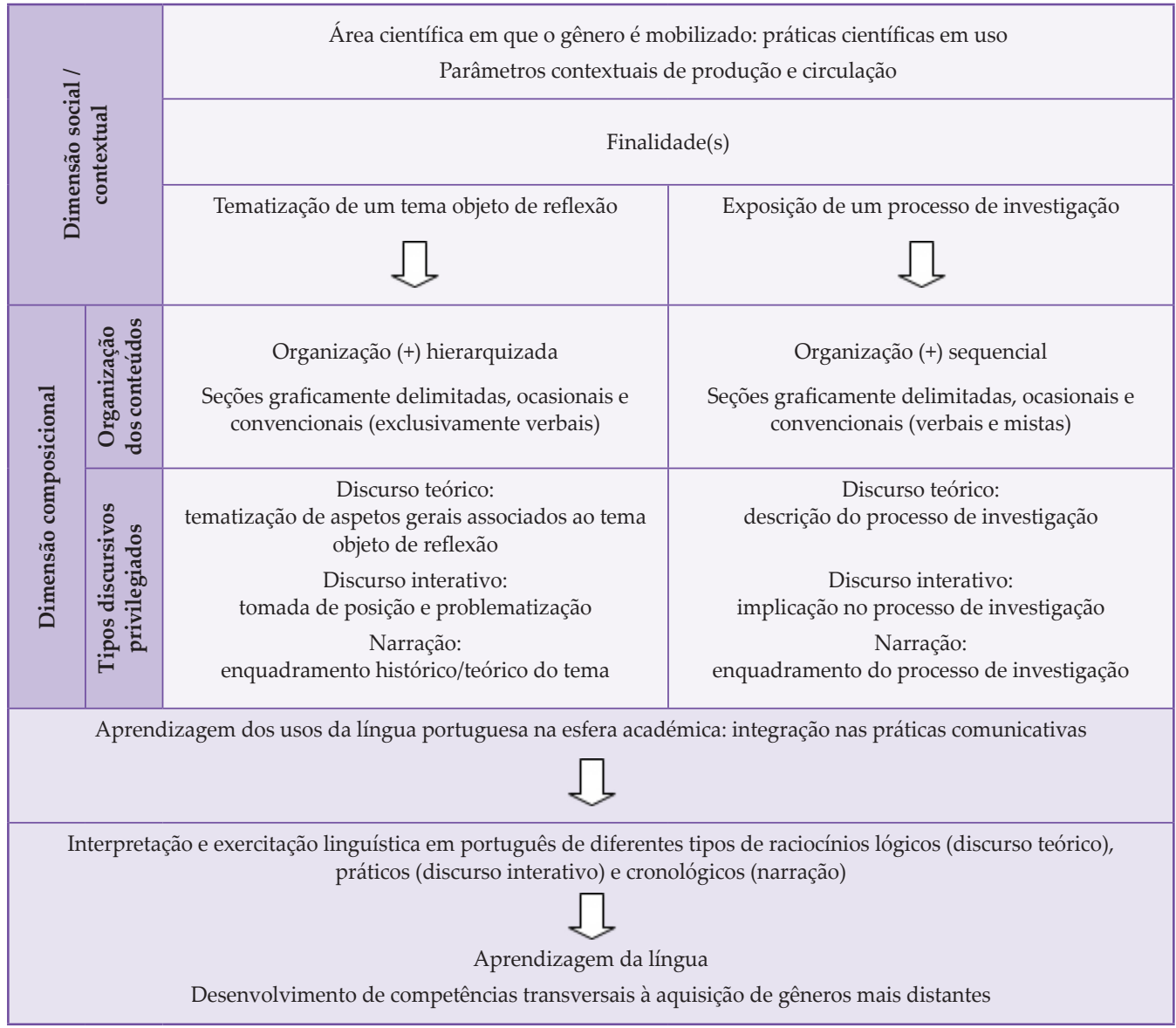

\section{CONSIDERAÇÕES FINAIS}

Neste trabalho, a partir da análise de textos empíricos, apresentamos um modelo didático do gênero artigo científico, destinado a orientar a intervenção dos professores de Português como Língua Adicional no contexto acadêmico português. Embora este dispositivo teórico não contemple todas as dimensões ensináveis do gênero, consideramos que o ensino destas características permitirá, por um lado, a aprendizagem dos usos da língua portuguesa na esfera acadêmica, contribuindo para integração dos estudantes nas práticas comunicativas e, por outro, desenvolver nos alunos competências necessárias à aprendizagem de outros gêneros acadêmicos, como, por exemplo, a dissertação, mas também competências transversais à aquisição de gêneros mais distantes e à aprendizagem da língua, nomeadamente a interpretação e exercitação linguística de diferentes tipos de raciocínios lógicos, práticos e cronológicos.

A partir deste modelo didático (dispositivo teórico), poderão ser desenvolvidas duas sequências didáticas (dispositivos práticos): uma focada na leitura e outra focada na escrita. Por último, importa sublinhar que o modelo didático apresentado constitui uma base orientadora do trabalho do professor e, por isso, deverá ser perspectivado de acordo com 
as especificidades do contexto de ensino, como, por exemplo, a área científica da licenciatura/mestrado, bem como os níveis de proficiência e a língua materna dos alunos.

\section{REFERÊNCIAS}

Adam, J. M. (2008). A linguística textual: Introdução à análise textual dos discursos. São Paulo: Cortez.

Bronckart, J. P. (1996). Genres de textes, types de discours et opérations psycholinguistiques. Voies livres, (78), 1-20.

Bronckart, J. P. (1999). Atividade de linguagem, textos e discursos: Por um interacionismo sócio-discursivo. São Paulo: EDUC.

Bronckart, J. P. (2004). Les genres de textes et leur contribution au développement psychologique. Langages, (153), 98-108. https://doi.org/10.18309/anp.v1i8.359

Bronckart, J. P. (2010). La vie des signes en questions: des textes aux langues et retour. In A. M. Brito, F. Silva, J. Veloso, \& Fiéis, A. (Eds.), Textos seleccionados do 25ํㅡㄹ Entro Nacional da Associação Portuguesa de Linguística (pp. 11-40). Porto: APL. https://doi. org/10.3406/lgge.2004.938

Buescu, H. C., Maia, L. C., Silva, M. G., \& Rocha, M. R. (Orgs.) (2014). Programa e metas curriculares de Português: Ensino secundário. Lisboa: Ministério da Educação e Ciência.

Buescu, H. C., Morais, J., Rocha, M. R., \& Magalhães V. F. (2015). Programa e metas curriculares de Português do ensino básico. Lisboa: Ministério da Educação e Ciência.

Coutinho, M. A. (2004). Organizadores textuais: Entre língua, discurso e gênero. In F. Oliveira, \& I. M. Duarte (Orgs.), Da língua e do discurso (pp. 283-298). Porto: Campo das Letras.

Coutinho, M. A. (2006). O texto como objecto empírico: Consequências e desafios para a linguística. Veredas: Revista de Estudos Linguísticos, 10(1-2). Recuperado de http://www. ufjf.br/revistaveredas/files/2009/12/artigo076.pdf

Coutinho, M. A. (2008). Marcadores discursivos e tipos de discurso. Estudos Linguísticos, 2, 193-210.

Coutinho, M. A. (s.d.). Gêneros de texto: Noção teórica e ferramenta didática. Recuperado de http://www.dge.mec.pt/sites/default/files/Formacao/es_conf_generos_texto_ac.pdf

Corno, G. O. M. D. (2001). O papel da pragmática na análise do livro didático para o ensino comunicativo de português do Brasil para estrangeiros (Dissertação de mestrado). Universidade Federal do Rio Grande do Sul, Porto Alegre. https://doi. org/10.29289/259453942018v28s1059

De Pietro, J. F., Erard, S., \& Kaneman-Pougatch, M. (1996). Un modèle didactique du "débat": De l'objet social à la pratique scolaire. Enjeux, 39/40, 100-129.

Gonçalves, M. (2011). Espécie de texto: Contributo para a caraterização do sítio web. Hipertextus Revista Digital, (7), 1-12.

Miranda, F. (2008). Gêneros de texto e tipos de discurso na perspetiva do interacionismo sociodiscursivo: Que relações? Estudos Linguísticos, (1), 81-100. 
Schneuwly, B. \& Joaquim, D. (1999). Os gêneros escolares: Das práticas de linguagem aos objetos de ensino. Revista Brasileira de Educação, (11), 5-16.

Schneuwly, B. \& Joaquim, D. (2004). Gêneros orais e escritos na escola. Campinas: Mercado das Letras.

Schoffen, J. R. (2009). Gênero do discurso e parâmetros de avaliação de proficiência em português como língua estrangeira no exame CELPE-Bras (Tese de Doutorado). Universidade Federal do Rio Grande do Sul, Porto Alegre. https://doi.org/10.29289/259453942018v28s1059

Silva, P. N. (2016). Gênero, conteúdos e segmentação: Em busca do plano de texto. Diacrítica, 30(1), 181-224.

Voloshinov, V. N. (1977). Le marxisme et la philosophie du langage. Paris: Minuit.

Submetido: $25 / 01 / 2019$

Aceito: $20 / 05 / 2019$

Publicado: 28/06/2019

\section{Autora:}

Rute Alves Rosa

Doutorado em andamento em Linguística, Faculdade de Ciências Sociais e Humanas da Universidade NOVA de Lisboa, Portugal.

Bolsista de pesquisa, Faculdade de Ciências Sociais e Humanas da Universidade NOVA de Lisboa, Portugal.

E-mail: ruterosa@fcsh.unl.pt

Orcid: http://orcid.org/0000-0003-2707-3624

Endereço: Universidade NOVA de Lisboa

Avenida Berna 26 C

1069-061, Lisboa, Portugal 